\title{
Toddler temperament and prenatal exposure to lead and maternal depression
}

\author{
Annemarie Stroustrup ${ }^{1,2,8^{*}}$, Hsiao-Hsien Hsu², Katherine Svensson², Lourdes Schnaas ${ }^{3}$, Alejandra Cantoral ${ }^{4}$, \\ Maritsa Solano González ${ }^{4}$, Mariana Torres-Calapiz ${ }^{3}$, Chitra Amarasiriwardena ${ }^{2}$, David C. Bellinger ${ }^{5,6}$, Brent A. Coull ${ }^{6,7}$, \\ Martha M. Téllez-Rojo ${ }^{4}$, Robert O. Wright ${ }^{1,2}$ and Rosalind J. Wright ${ }^{1,2}$
}

\begin{abstract}
Background: Temperament is a psychological construct that reflects both personality and an infant's reaction to social stimuli. It can be assessed early in life and is stable over time Temperament predicts many later life behaviors and illnesses, including impulsivity, emotional regulation and obesity. Early life exposure to neurotoxicants often results in developmental deficits in attention, social function, and IQ, but environmental predictors of infant temperament are largely unknown. We propose that prenatal exposure to both chemical and non-chemical environmental toxicants impacts the development of temperament, which can itself be used as a marker of risk for maladaptive neurobehavior in later life.

In this study, we assessed associations among prenatal and early life exposure to lead, mercury, poverty, maternal depression and toddler temperament.
\end{abstract}

Methods: A prospective cohort of women living in the Mexico City area were followed longitudinally beginning in the second trimester of pregnancy. Prenatal exposure to lead (blood, bone), mercury, and maternal depression were assessed repeatedly and the Toddler Temperament Scale (TTS) was completed when the child was 24 months old. The association between each measure of prenatal exposure and performance on individual TTS subscales was evaluated by multivariable linear regression. Latent profile analysis was used to classify subjects by TTS performance. Multinomial regression models were used to estimate the prospective association between prenatal exposures and TTS performance.

Results: 500 mother-child pairs completed the TTS and had complete data on exposures and covariates. Three latent profiles were identified and categorized as predominantly difficult, intermediate, or easy temperament. Prenatal exposure to maternal depression predicted increasing probability of difficult toddler temperament. Maternal bone lead, a marker of cumulative exposure, also predicted difficult temperament. Prenatal lead exposure modified this association, suggesting that joint exposure in pregnancy to both was most toxic.

Conclusions: Maternal depression predicts difficult temperament and concurrent prenatal exposure to maternal depression and lead predicts a more difficult temperament phenotype in 2 year olds. The role of temperament as an intermediate variable in the path from prenatal exposures to neurobehavioral deficits and other health effects deserves further study.

Keywords: Temperament, Prenatal exposure, Lead, Depression in pregnancy, Neurobehavioral outcomes

\footnotetext{
* Correspondence: annemarie.stroustrup@mssm.edu

${ }^{1}$ Department of Pediatrics, Icahn School of Medicine at Mount Sinai, New

York, NY, USA

${ }^{2}$ Department of Preventive Medicine, Icahn School of Medicine at Mount

Sinai, New York, NY, USA

Full list of author information is available at the end of the article
} 


\section{Background}

Temperament reflects the manner in which an individual interacts with and responds to social and emotional environmental cues. Distinct temperament traits are identifiable in infancy and are relatively stable over time [1, 2]. Temperament is a biologically based trait [3] and is associated with later child behavior, both normal and pathological [4-7]. Early childhood temperament can be seen as an important risk factor for behavioral problems that are not expressed until later in life as well as for diseases such as obesity [8-14]. While the full range of risk factors that predict maladaptive temperament are not wellunderstood, it is believed that temperament is established during perinatal life through both genetic and environmental factors [13-16]. As such, in utero exposure to neurotoxicants might impact infant temperament, and maladaptive temperament may be an early life intermediate phenotype for behavioral disorders brought on by environmental toxicants.

Although prenatal exposure to elemental metals including lead and mercury is known to be detrimental to cognition and specific behavioral domains in childhood [1723], the relationship between in utero metal exposure and temperament has not been studied previously. Social stressors such as maternal mental state and stress level which we refer to as "non-chemical toxicants" [24] - can also have a significant clinical impact on the developing fetus [25-30]. Women who experience toxic stress, anxiety, or depression while pregnant have children at elevated risk for certain physical, cognitive, and behavioral difficulties [28-32]. To our knowledge, no study has attempted to address whether concurrent prenatal exposure to chemical and non-chemical stressors interact to predict maladaptive temperament phenotypes.

While gene-environment interactions have received much attention, the concurrent exposure to multiple toxins may also multiplicatively increase effects seen in single exposure models [33-42], and studies of prenatal exposure should evaluate both chemical and non-chemical exposures to reflect real-life exposure scenarios. In this study, we hypothesized that prenatal co-exposure to chemical and non-chemical neurotoxicants is associated with difficult infant temperament. The study was nested in a large prospective environmental health cohort study designed to investigate the impact of concurrent prenatal exposure to lead, mercury, maternal depression, socioeconomic status, and maternal nutrition on multiple long-term neurobehavioral outcomes.

\section{Methods}

Participant identification and enrollment

Between 2007 and 2011, healthy pregnant women in Mexico City were recruited through the Mexican Social Security System to participate in the PROGRESS
(Programming Research in Obesity, GRowth, Environment, and Social Stress) birth cohort [43]. Informed consent to participate in the study was obtained from participants. Nine hundred forty-eight women were enrolled prior to 20 weeks of pregnancy and delivered a live infant. Of these, 760 children were evaluated for neurodevelopment in at least one visit at $6,12,18$, or 24-months of age. Of the 549 completing the 24-month visit, 500 mothers responded to the Toddler Temperament Scale (TTS), the primary outcome in these analyses. Research ethics committees of the participating institutions approved the study (the Comité de Investigación, Comité de Bioseguridad, and the Comité de Ética en la Investigación of the National Institute of Public Health, Mexico, the Partners Human Research Committee at Brigham and Women's Hospital, the Office of Human Research Administration at the Harvard School of Public Health, and the Program for the Protection of Human Subjects at the Icahn School of Medicine at Mount Sinai).

\section{Participant data collection}

Questionnaires were administered to collect sociodemographic information including maternal age, parity, education level, and socioeconomic status (SES). Thirteen variables derived from questionnaire results were used to classify study participant families into six levels based on the SES index created by the Asociación Mexicana de Agencias de Investigación de Mercados y Opinión Pública [44]. These levels were then collapsed into low, medium, and high socioeconomic status.

\section{Lead measurements}

Maternal lead exposure was assessed by inductively coupled plasma-mass spectrometry (Agilent 8800, Santa Clara, CA) of maternal blood during the second trimester and in bone by maternal in vivo $\mathrm{K}$-shell X-ray fluorescence (K-XRF) one month postpartum (ABIOMED, Danvers, MA, USA) $[45,46]$. Blood lead measurement quality control (QC) and quality assurance procedures used were: included analyses of procedural blanks, duplicates, spiked samples, national institute of standard reference material (NIST SRM) 955 (Lead in Blood); NIST SRM 1643e (trace elements in water) and blood samples from the interlaboratory study program INSPQ/Laboratoire de Toxicologie, Quebec to monitor the accuracy and recovery rates of the procedure for each analytic batch. Lab recovery rates for QC standards and spiked samples with this method were 9- $110 \%$ and precision (given as \% RSD) was $<5 \%$. The limit of detection for this procedure was $0.2 \mathrm{ng} \mathrm{ml-1}$.

Our K-XRF protocol measures bone lead at the midshaft tibia (cortical bone) and the patella (trabecular bone) [47] to provide a representation of cumulative fetal lead exposure through gestation $[45,48]$. K-XRF produces 
negative values when the bone lead content is below the detection limit of the instrument. As imputation to replace negative values in this context has not been shown to be beneficial [49], we included negative values as reported by K-XRF in our analyses.

\section{Mercury measurements}

Maternal mercury exposure was evaluated by measuring mercury deposition in maternal toenails collected during pregnancy. Toenails from all ten toes were collected and pre-cleaned by sonicating for $15 \mathrm{~min}$ in approximately $10 \mathrm{~mL}$ of $1 \%$ Triton X-100 solution to remove extraneous contaminants. Samples were then rinsed with distilled deionized water and dried at $60{ }^{\circ} \mathrm{C}$ for $24 \mathrm{~h}$ in a drying oven. Mercury level was assessed using the Direct Mercury Analyzer 80 (Milestone Inc., Monroe, CT) using previously published methods [50]. Samples were analyzed using an aqueous calibration standards and verifyied using different weights of certified reference material GBW 07601 (human hair; Institute of Geophysical and Geochemical Exploration, China). Mercury recovery was 90-110\%, with greater than $90 \%$ precision. The detection limit for samples varied according to sample weight. Sample weight varied from $0.006 \mathrm{~g}$ to $0.0 .083 \mathrm{~g}$, and the detection limit varied from $0.006 \mu \mathrm{g} / \mathrm{g}$ to $0.08 \mu \mathrm{g} / \mathrm{g}$ (mean $=0.019 \mu \mathrm{g} / \mathrm{g})$.

\section{Measurements of child development}

All children were assessed for motor, language and cognitive development using the Bayley Scales of Infant and Toddler Development, 3rd edition (BSID) at 24 months of age [51]. Child temperament was assessed at 24 months of age using the TTS [2], which comprises a number of ageappropriate questions. These questions evaluate the nine temperamental characteristics first described by Thomas et al. [52], and expands on earlier work by Carey measuring temperament in infants $[53,54]$. Caregivers are presented with a statement describing a certain behavior and asked to rate how often their child behaves in that way on a 6point scale. The results are coded so that higher scores indicate more difficult temperament. Although the TTS is designed to be completed independently by parents, in the current study trained psychologists verbally administered the TTS to the enrolled mother at the 24-month study visit. In 9 cases where the mother was not present at the 24-month visit, the TTS questionnaire was mailed to the home for independent completion by the mother.

\section{Measurement of maternal depression risk}

The Edinburgh Postnatal Depression Scale (EPDS) was administered to mothers in the second trimester. The EPDS is a ten-item self-report scale designed to identify women experiencing depressive symptoms [55]. It is validated for repeated use during and both immediately and long after pregnancy [56, 57]. For these analyses, the second trimester EPDS result was used as the prenatal depression risk score. If the EPDS was not administered during the second trimester, the third trimester result was used as the prenatal depression risk score. The 24-month EPDS score was obtained at the same study visit as the TTS. Depression risk was evaluated both as a continuous and as a categorical variable dichotomized at an EPDS score of 13, the recommended cut point $[55,58,59]$.

Although the focus of this study was to prospectively evaluate the impact of prenatal exposures including maternal depression, we also evaluated the EPDS score obtained cross-sectionally at child age 24-months in analyses, as the caregiver's mental state at the time of TTS administration has been associated with the assessment of the child's temperament [60,61]. As in other studies where depressive symptoms years after childbirth were associated with perinatal depression $[62,63]$, the categorical variable for prenatal maternal depression risk was associated with depression risk at 24 months $(p<0.001)$, and the continuous variables were correlated $(\rho=0.66)$ in our cohort. To address the collinearity induced by including both antenatal and 24-month post-partum depression in the same model, we included variables for both the average of the two scores and the difference between scores in all analyses using the EPDS continuous variable. This transformation from the original correlated measurements to the sum and difference is the basis for traditional MANOVA analyses for multivariate outcomes [64]. The adjusted representation of the prenatal maternal depression score is referred to as "adjusted EPDS" or "adjusted prenatal depression" throughout this manuscript.

\section{Statistical approach \\ Linear regression modeling}

We examined univariate descriptive statistics, bivariate associations, and multivariable linear regression of each of the 9 TTS subscales using multiple measures of prenatal lead exposure, prenatal mercury exposure, maternal education, SES index, maternal ferritin during pregnancy (as a marker of nutritional status), and prenatal maternal depression score. Interaction terms for different exposures were also examined. Initial models included maternal ferritin and education, but these were dropped from subsequent models as they were insignificant (ferritin) or strongly correlated with the SES index (maternal education). These analyses were conducted using SAS 9.4 (Research Triangle Institute, Cary, NC).

In order to reduce the dimensionality of the overall nine outcome scale into a smaller set of discrete categories, we also used latent profile analysis (LPA) to evaluate associations between multiple prenatal exposures and temperament phenotype. 


\section{Latent profile analysis}

Latent profile analysis (LPA) is a probabilistic, model-based variant of traditional nonhierarchical cluster analysis [65]. We used it to objectively classify children into discrete data-driven temperament profiles. LPA assumes that the population consists of a number of unobserved subgroups that are referred to as latent profiles. Individuals within a given latent profile will show similarities in their TTS subscales scores. For example, children in the same latent profile may demonstrate a high score on subscales for mood, activity and approach, low scores on rhythmicity and adaptability, and intermediate scores on the remaining subscales. Sharing a latent profile does not require consistent high or low scoring across all subscales. Rather, it identifies groups of subjects who have a similar performance pattern globally. Because the TTS assesses multiple behavioral domains that contribute to complex temperament phenotypes, we used LPA to reduce the temperament subscale data into discrete categories. We used Bayesian information criteria (BIC) whereby the smallest $\mathrm{BIC}$ value indicates the best fit as well as minimizes cross-classification probabilities. BIC has been shown to identify the appropriate number of profiles in finite mixture models [66] and penalizes the models for a number of parameters that may indicate model over-fit. LPA was implemented on the nine TTS subscales by using a normal mixture model as a model-based clustering technique, as fitted via an expectation- maximization algorithm in the mclust $4.3 \mathrm{R}$ software package [67].

\section{Multinomial logistic regression}

Multinomial Logistic Regression (MLR) is an extension of logistic regression, which analyzes dichotomous variables. In multinomial logistic regression analysis, three or more dependent nominal variables (i.e. not clearly in defined order) are regressed choosing one as the referent group. Our LPA defined three groups (Fig. 1), two of which we could clearly categorize as easy vs difficult, with the third group being intermediate. Upon selection of a final latent class fit, we used MLR analysis to evaluate concordance between identified TTS profiles and performance on the BSID, to confirm that the identified profiles represented behaviorally consistent groupings. Based on prior noted associations between temperament and language performance [52, 68-70], we expected children with the more difficult temperament profile to be associated with worse performance on BSID measures of language. We then regressed our prenatal exposures of interest with the LPA categories [69]. Specifically, MLR was used to evaluate associations between TTS profiles and measures of prenatal lead exposure, $\mathrm{Hg}$ exposure, SES, and maternal depression using "easy" as the referent group. Blood lead levels were natural log transformed. Probabilistic models were built to evaluate the association between temperament profile and concurrent exposure to

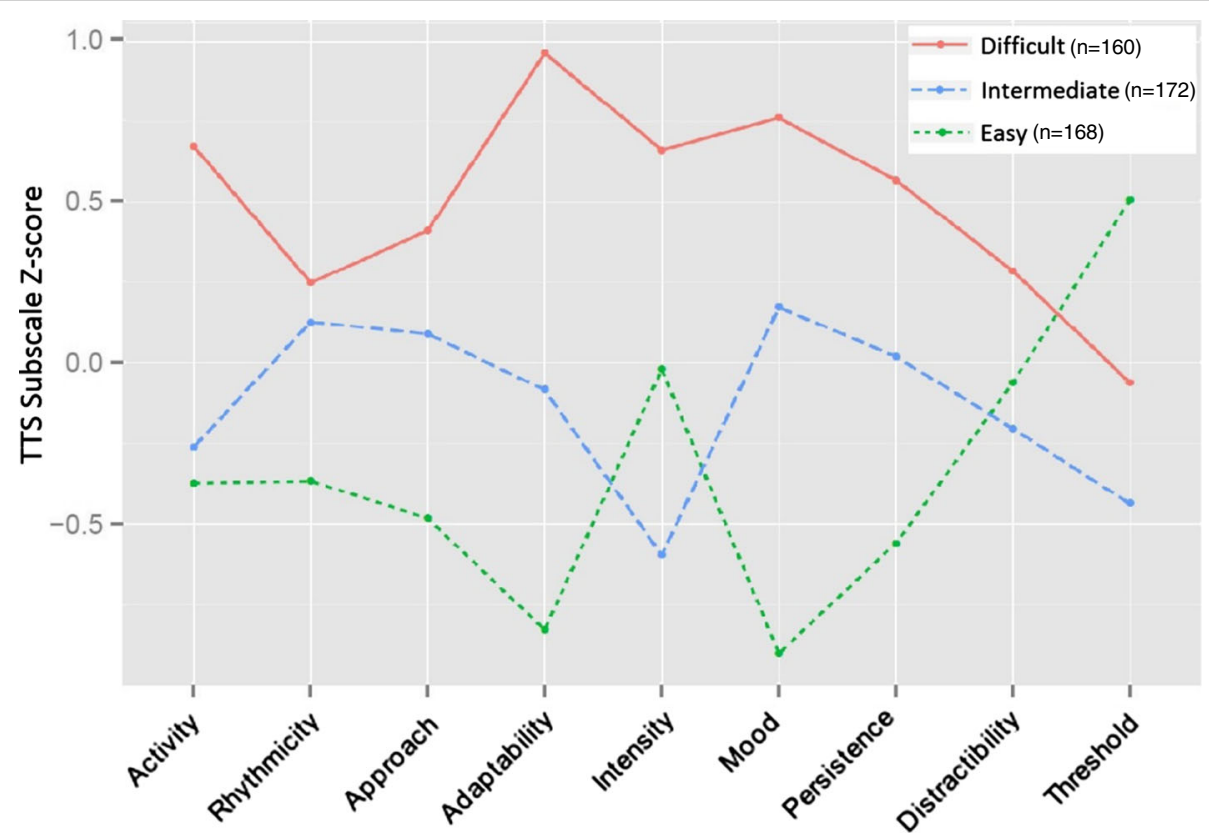

Fig. 1 Distribution of TTS Subscale Performance Z-scores by Latent Profiles. Although each profile demonstrates a mix of "easy", "intermediate", and "difficult" temperamental traits on varying subscales, profile 1 children generally demonstrated a more difficult temperament, profile 2 generally demonstrated more intermediate temperamental traits, and profile 3 children generally demonstrated an easy temperament 
varying levels of prenatal factors that were found to be significant in single exposure models. LPA modeling and graphics were completed using R ( $\mathrm{R}$ Core Team, Vienna, Austria, 2014) [71].

\section{Results}

Table 1 summarizes the demographic data on the 500 mother-infant pairs included in these analyses. Our study cohort, those who completed the TTS, were significantly more likely to be of low SES and less likely to be of high SES than PROGRESS participants who did not complete the TTS $(p=0.03)$. There were no other significant demographic differences between the groups. Table 2 presents associations between chemical and non-chemical prenatal exposures and scores on individual TTS subscales. Adjusted prenatal depression risk score, SES classification, maternal tibia lead K-XRF, and prenatal maternal toenail mercury levels were associated with TTS subscale performance in single exposure models. Interaction models including adjusted prenatal depression risk score and either second trimester maternal blood lead, maternal tibia lead K-XRF, or second trimester maternal toenail mercury were also significantly associated with certain TTS subscales

Neither maternal patella K-XRF, nor interaction models using patella lead measurement and adjusted prenatal depression risk were associated with TTS subscale scores. Similarly, interaction models between prenatal mercury level and any measure of prenatal lead exposure were not significantly associated with TTS subscale performance (results not shown).
Our LPA demonstrated three discrete profiles (Fig. 1). Children fell into three categories of temperament, two of which could be characterized as difficult (more intense, less regulated, etc.), versus easy-going (less intense, more regulated, etc.). The third category appears to be intermediate, with performance in the moderate range for most subscales. To confirm that our LPA profiles represent neurobehaviorally meaningful groupings, we evaluated the relationship between our study's TTS profiles and language performance on the BSID. Figure 2 shows how children in each profile performed on the BSID language elements. Consistent with studies in other populations $[68,70,72]$, more difficult toddler temperament was significantly associated with worse performance on tests of language ability in our cohort.

We next tested whether the probability of a subject demonstrating a given TTS profile varied in relation to prenatal exposures. Results of multinomial logistic regression analyses of the relationship between prenatal exposures and TTS latent profile are summarized in Table 3. Greater prenatal exposure to maternal depression estimated by the adjusted prenatal EPDS, and to lead estimated either by maternal blood lead level or K-XRF of the maternal tibia, was associated with significantly increased odds of having a difficult temperament. Prenatal SES, maternal patella lead measurement, and antenatal maternal toenail mercury level were not significantly associated with the temperament classification.

Finally, we addressed concurrent prenatal exposure to factors significant in single predictor models. Figure 3 demonstrates the probability of demonstrating each of the three temperament profiles ( $y$-axis) stratified by adjusted

Table 1 Characteristics of the study cohort compared to the parent PROGRESS cohort and the general Mexican population

\begin{tabular}{|c|c|c|c|}
\hline Participant Characteristics & Mexican population [44] & $\begin{array}{l}\text { Selected study } \\
\text { cohort }(n=500)\end{array}$ & $\begin{array}{l}\text { PROGRESS families not in } \\
\text { the selected cohort }(n=260)\end{array}$ \\
\hline \multicolumn{4}{|l|}{ Continuous variables } \\
\hline Maternal age (years) & & $26.9 \pm 5.5$ & $27.3 \pm 5.3$ \\
\hline Maternal 2nd trimester blood Pb, (median (IQR), ug/dL) & & $2.8(2.7)$ & $2.8(2.4)$ \\
\hline Maternal postpartum tibia $\mathrm{Pb}$ (mean $\pm \mathrm{SD}$, ug/g bone mineral) & & $2.6 \pm 8.6$ & $2.7 \pm 8.3$ \\
\hline Maternal postpartum patella $\mathrm{Pb}$ (mean $\pm \mathrm{SD}$, ug/g bone mineral) & & $4.9 \pm 8.9$ & $4.3 \pm 8.0$ \\
\hline Maternal EPDS score, 2nd or 3rd trimester (mean \pm SD) & & $8.3 \pm 5.7$ & $8.9 \pm 6.0$ \\
\hline \multicolumn{4}{|l|}{ Categorical variables } \\
\hline \multicolumn{4}{|l|}{ Maternal education } \\
\hline More than high school & & $117(23.4 \%)$ & $60(23.1 \%)$ \\
\hline High school & & $171(34.2 \%)$ & $104(40.0 \%)$ \\
\hline Less than high school & & $212(42.4 \%)$ & $96(36.9 \%)$ \\
\hline \multicolumn{4}{|l|}{ Socioeconomic index } \\
\hline High & $21.2 \%$ & $46(9.2 \%)$ & $33(12.7 \%)$ \\
\hline Middle & $53.7 \%$ & $177(35.4 \%)$ & 105 (40.4 \%) \\
\hline Low & $25 \%$ & 277 (55.4 \%) & $122(46.9 \%)$ \\
\hline
\end{tabular}




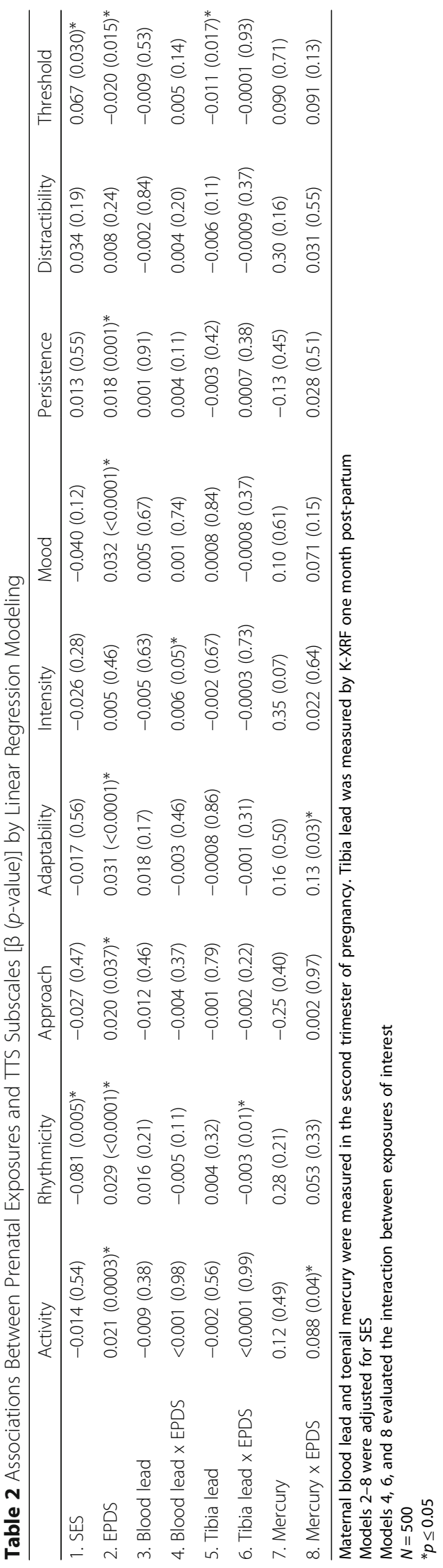




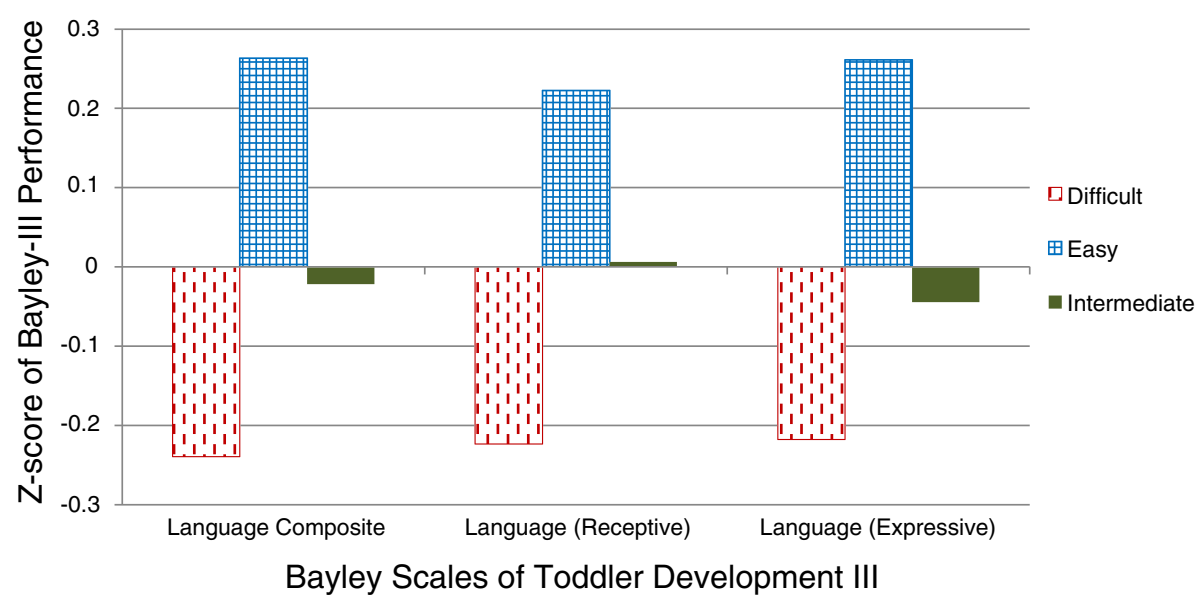

Fig. 2 Performance on the Language Scales of the BSID by Temperament Profile. As expected based on prior studies of temperament and language ability [68, 70,72], children in the easy temperament profile performed well while children in the difficult temperament profile performed poorly

prenatal EPDS score dichotomized at 13, and illustrates the joint impact of exposure to increasing prenatal lead exposure (x-axis) and for high or low maternal depression score (dotted versus solid lines). High adjusted prenatal depression scores increased the probability that a child demonstrated a difficult temperament. When tibia lead concentration and adjusted prenatal depression score were low $\left(25^{\text {th }}\right.$ percentile or lower), a child demonstrated an easy or intermediate temperament approximately $70 \%$ of the time. As prenatal lead exposure increased, the probability of demonstrating an easy or intermediate temperament fell and the probability of demonstrating a difficult temperament rose. This effect was more pronounced when the adjusted prenatal depression risk score was high. Similar results were seen when maternal blood lead was used as a measure of prenatal lead exposure, although results were less significant. Prenatal mercury exposure did not alter the effect of prenatal maternal depression on temperament (results not shown).

\section{Discussion}

While associations between prenatal exposure to metals or maternal depression and cognitive development have been widely reported $[12,13,20,44-47]$, the role of such exposures in early life behavioral development is less well-understood. Effects seen in behavior early in life can help to parse the contribution of prenatal vs later life exposures, since exposures through the life-course are often correlated. Also, early life behavioral changes that result from environmental exposures may serve as intermediates for later life behavioral phenotypes, helping us to understand the complex interrelationships among exposure and behavioral development. Environmental health research focused on intelligence has generated a great appreciation for the impact of perinatal environmental exposures on ultimate IQ and intellectual achievement. However, learning and intellectual performance are complex processes that clearly interact with behavioral traits to produce psychological health. The importance of behavioral traits to overall child development is becoming increasingly apparent [73]. Cognition and cognitive performance is dependent on many behavioral traits such as attention and impulsivity that integrate with intellectual processes such as memory and mathematical ability in everyday life. To better understand central nervous system toxicity, the role of toxins in altering behavioral development and cognitive traits should be considered equally important. Prenatal and

Table 3 Associations Between Prenatal Exposures and TTS Profile by Multinomial Logistic Regression Modeling

\begin{tabular}{|c|c|c|c|c|c|c|c|c|c|c|c|c|c|c|c|c|c|c|}
\hline \multirow{3}{*}{$\frac{\text { Temperament }}{\text { Easy }}$} & \multicolumn{3}{|c|}{ EPDS $^{a}$} & \multicolumn{3}{|l|}{ SES } & \multicolumn{3}{|c|}{ Blood lead ${ }^{b}$} & \multicolumn{3}{|c|}{ Tibia lead $^{c}$} & \multicolumn{3}{|c|}{ Patella lead $^{c}$} & \multicolumn{3}{|c|}{ Mercury $^{c}$} \\
\hline & \multirow{2}{*}{$\begin{array}{l}\text { OR } \\
\text { Ref }\end{array}$} & \multicolumn{2}{|c|}{$95 \% \mathrm{Cl}$} & \multirow{2}{*}{$\begin{array}{l}\mathrm{OR} \\
\text { Ref }\end{array}$} & \multicolumn{2}{|c|}{$95 \% \mathrm{Cl}$} & \multirow{2}{*}{$\begin{array}{l}\text { OR } \\
\text { Ref }\end{array}$} & \multicolumn{2}{|c|}{$95 \% \mathrm{Cl}$} & \multirow{2}{*}{$\begin{array}{l}\text { OR } \\
\text { Ref }\end{array}$} & \multicolumn{2}{|c|}{$95 \% \mathrm{Cl}$} & \multirow{2}{*}{$\begin{array}{l}\text { OR } \\
\text { Ref }\end{array}$} & \multicolumn{2}{|c|}{$95 \% \mathrm{Cl}$} & \multirow{2}{*}{$\begin{array}{l}\text { OR } \\
\text { Ref }\end{array}$} & \multicolumn{2}{|c|}{$95 \% \mathrm{Cl}$} \\
\hline & & - & - & & - & - & & - & - & & - & - & & - & - & & - & - \\
\hline Intermediate & 1.23 & 0.78 & 1.93 & 0.71 & 0.26 & 1.9 & 0.88 & 0.59 & 1.3 & 1.25 & 0.95 & 1.65 & 0.99 & 0.96 & 1.02 & 0.82 & 0.11 & 6.15 \\
\hline Difficult & 2.53 & 1.69 & 3.77 & 1.38 & 0.46 & 4.15 & 1.52 & 1.03 & 2.26 & 1.32 & 1.01 & 1.73 & 1.01 & 0.98 & 1.04 & 1.89 & 0.29 & 12.28 \\
\hline
\end{tabular}

${ }^{a}$ Odds ratio (OR) and $95 \% \mathrm{Cl}$ corresponding to IQR change in adjusted EPDS score (IQR $=7.3$ )

${ }^{\mathrm{b}} \mathrm{OR}$ and $95 \% \mathrm{Cl}$ corresponding to 1 unit change of $\ln$ (maternal blood lead ug/dl), which corresponds to a 2.7 fold increase in second trimester maternal blood lead level

${ }^{\mathrm{C}} \mathrm{OR}$ and $95 \% \mathrm{Cl}$ corresponding to per 1 unit change per $10 \mathrm{ug} / \mathrm{g}$ change in metal measurement 


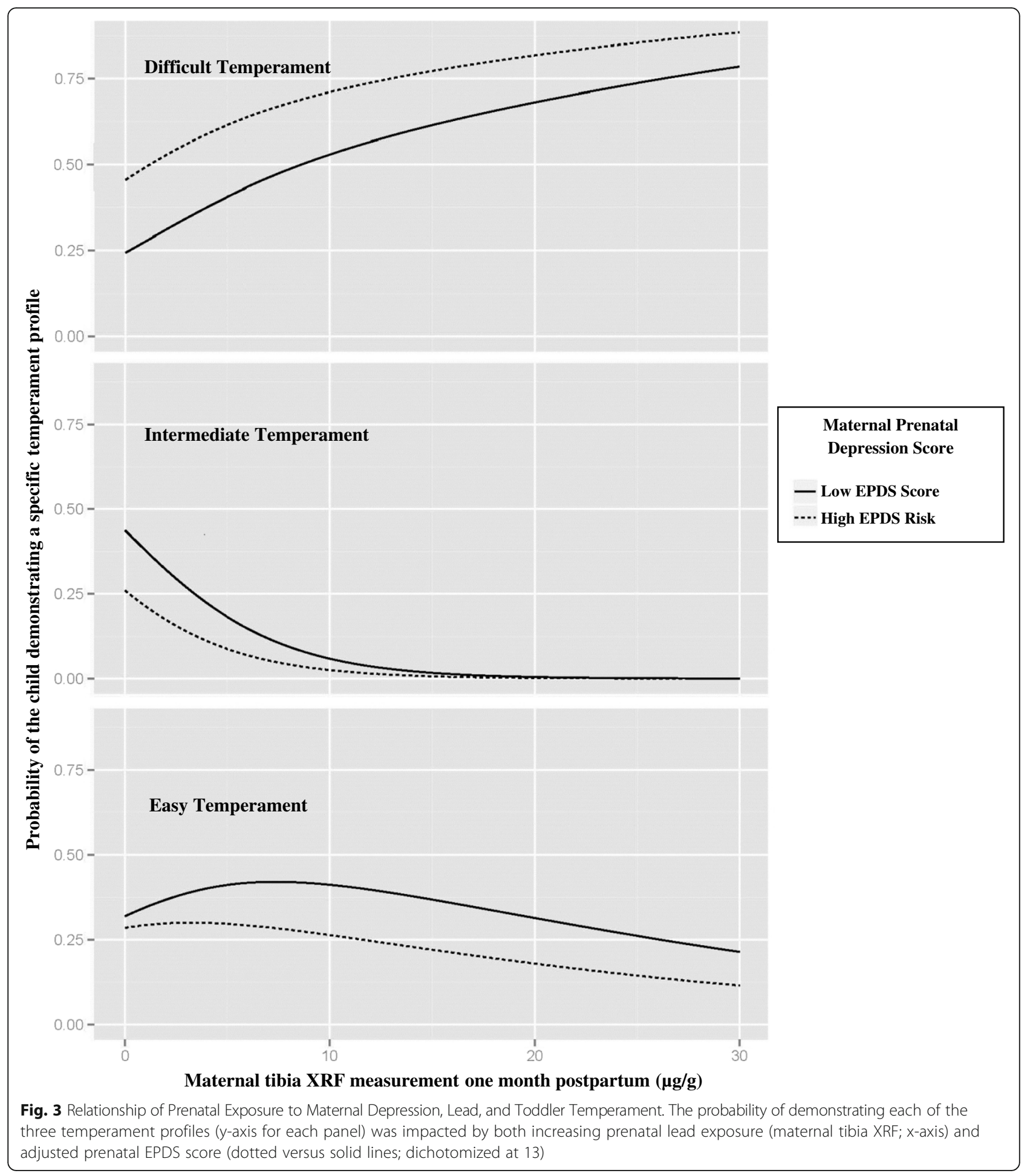

childhood exposure to maternal depression [74-76], lead $[17,77-79]$, and mercury $[18,22,80]$ have been associated with behavior problems from middle childhood through adolescence. Measurable early life behaviors, such as temperament, predict psychiatric traits later in life including externalizing and internalizing disorders in school age children and ADHD [81, 82]. If early life temperament is predictive of later life psychiatric traits, then our results suggest that cumulative lead exposure and maternal depression may set these trajectories as early as age two. If we are to develop effective treatments or prevention measures for behavioral disorders, we need to both better 
understand the role of exposure timing and develop methods for early detection of deficits so that developmental plasticity can be leveraged to mitigate the neurotoxic effects of chemical and non-chemical exposures. Evaluation of temperament may provide this intermediate outcome as both sensitive to environmental exposures and measurable at a point in development when effective interventions can be initiated to reduce longterm morbidity.

Our data demonstrate a relationship between cumulative prenatal lead exposure and the likelihood of demonstrating a difficult temperament. Additionally, those mothers in our cohort with highest scores on prenatal depression screening had toddlers most likely to demonstrate difficult temperament traits, even after adjusting for maternal depression at the time of temperament assessment. As shown in Fig. 3, the association of cumulative prenatal lead exposure with difficult temperament was most pronounced among toddlers whose mothers had the highest adjusted prenatal depression scores. This indicates that both prenatal lead exposure and exposure to prenatal maternal depression impact the developing temperament of the child. The inclusion in our models of the mother's prenatal depression score adjusted for the 24-month post-partum depression risk scores allows us to differentiate an association between prenatal depression risk and temperament from the known association between concurrent maternal depression and maternal report of difficult temperament. Prenatal mercury exposure and SES did not modify the effect of prenatal depression on infant temperament in our analyses.

The impact of in utero exposure to maternal depression and/or environmental chemicals on temperament and the interplay of multiple co-exposures on the establishment of temperament have not been evaluated previously. Our data suggest that cumulative lead exposure rather than a single second trimester lead measurement best predicts the lead-temperament association and that the joint impact of lead and prenatal depression is most predictive of difficult temperament. Tibia bone lead level, which has a half-life of 12 years or more, reflects cumulative lead exposure over the mother's life-time [46, 83]. Previous studies have demonstrated that bone lead is a better predictor of infant development than blood lead, perhaps due to its longer half-life $[48,84]$. However, bone lead cannot distinguish whether there is a specific window of sensitivity for lead exposure. Understanding the role of exposure timing could allow us to develop early intervention strategies.

As the PROGRESS cohort ages, we are measuring other neurobehavioral domains, such as attention, impulsivity, spatial memory, motivation, time estimation and internalizing/externalizing behaviors to further assess the impact of exposure to metals and maternal depression on child behavioral development. We will also address the role of temperament as a predictor of these neurobehavioral phenotypes.

Our study has a number of strengths. As a large, prospective birth cohort study focused on perinatal environmental exposures, both social and chemical environmental factors were assessed prospectively and longitudinally multiple times through pregnancy and early childhood. The EPDS, the BSID and the TTS are validated research measures that were administered by trained study staff, all of whom had masters or doctoral degrees in child psychology. Our statistical approach using LPA reduced the dimensionality of the multiple outcome subscales into a single 3 level index that clearly identified distinct phenotypes similar to those described in prior studies of infant temperament. The relationship of these three phenotypes with BSID performance further allowed us to validate our LPA profiles. Collecting multiple measures of lead exposure allowed us to distinguish between effects of blood lead level at a specific time point as well as cumulative lead.

Our study also has some limitations. The study population is composed of families in urban Mexico, and results may not be fully generalizable to other populations in other settings. Lead exposure in our cohort is generally higher and SES lower than in the United States, but this allows us to test our hypotheses more cost-effectively. Maternal depression was estimated by the EPDS, which is a screening rather than a diagnostic tool, so some women who had positive screens may not have met diagnostic criteria for clinical depression. As is the case for most assessment tools of temperament in childhood, the TTS relies on subjective maternal report.

\section{Conclusions}

Prenatal exposure to maternal depression is associated with more difficult temperament traits at age two. This association is potentiated by concurrent prenatal exposure to environmental lead.

\section{Abbreviations \\ BIC, Bayesian information criteria; BSID, Bayley Scales of Infant and Toddler Development III; Cl, confidence interval; EPDS, Edinburgh Postnatal Depression Scale; IQR, interquartile range; K-XRF, K-shell X-ray fluorescence; LPA, latent profile analysis; $\mathrm{OR}$, odds ratio; SD, standard deviation; SES, socioeconomic status; TTS, Toddler Temperament Scale}

\section{Acknowledgements}

Dr. Stroustrup is supported by grant K23ES022268 from the National Institutes of Environmental Health Sciences (NIEHS). Additional funding for the investigators and this project comes through NIEHS grants R01ES013744, R01ES014930, R01ES021357, P30ES023515, and P42ES016454. The investigators would also like to acknowledge el Centro Medico ABC and the National Institute of Perinatology (Mexico) for provision of medical facilities used in study subject recruitment and evaluation.

\section{Funding source}

Dr. Stroustrup is supported by grant K23ES022268 from the National Institutes of Environmental Health Sciences (NIEHS). Additional funding for the investigators 
and this project comes through NIEHS grants R01ES013744, R01ES014930, R01ES021357, P30ES023515, and P42ES016454 and the National Institute of Public Health in Mexico.

\section{Availability of data and supporting materials}

The dataset and novel code supporting the conclusions of this article are available in the Open Science Framework repository osf.io/73qxe (https://osf.io/73qxe).

\section{Authors' contributions}

AS conceptualized and designed the study, carried out the initial analyses, drafted the initial manuscript, and approved the final manuscript as submitted. $\mathrm{HHH}$ conceptualized and designed the study, carried out the initial analyses, reviewed and revised the manuscript, and approved the final manuscript as submitted. KS carried out the initial analyses, reviewed and revised the manuscript, and approved the final manuscript as submitted. LS, AC, MSG MTC, and MTR designed the data collection instruments, coordinated and supervised data collection, critically reviewed the manuscript, and approved the final manuscript as submitted. CA completed laboratory analyses, reviewed and revised the manuscript, and approved the final manuscript as submitted. DCB critically reviewed the manuscript and approved the final manuscript as submitted. BAC conceptualized and designed the statistical analyses, reviewed and revised the manuscript, and approved the final manuscript as submitted. ROW, RJW, and MTR conceptualized and designed the study, reviewed and revised the manuscript, and approved the final manuscript as submitted.

\section{Competing interests}

The authors declare that they have no competing interests.

\section{Consent for publication}

Not applicable.

\section{Ethics approval and consent to participate}

Research ethics committees of the participating institutions approved the study (the Comité de Investigación, Comité de Bioseguridad, and the Comité de Ética en la Investigación of the National Institute of Public Health, Mexico, the Partners Human Research Committee at Brigham and Women's Hospital, the Office of Human Research Administration at the Harvard School of Public Health, and the Program for the Protection of Human Subjects at the Icahn School of Medicine at Mount Sinai).

\section{Financial disclosure}

The authors have no financial relationships relevant to this article to disclose.

\section{Author details}

'Department of Pediatrics, Icahn School of Medicine at Mount Sinai, New York, NY, USA. ${ }^{2}$ Department of Preventive Medicine, Icahn School of Medicine at Mount Sinai, New York, NY, USA. ${ }^{3}$ Department of Developmental Neurobiology, National Institute of Perinatology, Mexico City, Mexico. ${ }^{4}$ Center for Nutrition and Health Research, National Institute of Public Health, Morelos, Mexico. ${ }^{5}$ Departments of Neurology and Psychiatry, Boston Children's Hospital, Harvard Medical School, Boston, MA, USA. ${ }^{6}$ Department of Environmental Health, Harvard School of Public Health, Boston, MA, USA. ${ }^{7}$ Department of Biostatistics, Harvard School of Public Health, Boston, MA, USA. ${ }^{8}$ Division of Newborn Medicine, Department of Pediatrics, Icahn School of Medicine at Mount Sinai, One Gustave L. Levy Place, Box 1508, New York, NY 10029, USA.

Received: 7 March 2016 Accepted: 30 May 2016 Published online: 16 June 2016

\section{References}

1. Bagner DM, Rodriguez GM, Blake CA, Linares D, Carter AS. Assessment of behavioral and emotional problems in infancy: a systematic review. Clin Child Fam Psychol Rev. 2012;15(2):113-28.

2. Fullard W, McDevitt SC, Carey WB. Assessing temperament in one- to three-year-old children. J Pediatr Psychol. 1984:9(2):205-17.

3. Papageorgiou KA, Ronald A. "He who sees things grow from the beginning will have the finest view of them" a systematic review of genetic studies on psychological traits in infancy. Neurosci Biobehav Rev. 2013;37(8):1500-17.
4. Mclnerny T, Chamberlin RW. Is it feasible to identify infants who are at risk for later behavioral problems? The Carey Temperament Questionnaire as a prognostic tool. Clin Pediatr (Phila). 1978;17(3):233-8.

5. Sayal K, Heron J, Maughan B, Rowe R, Ramchandani P. Infant temperament and childhood psychiatric disorder: longitudinal study. Child Care Health Dev. 2014:40(2):292-7.

6. Teerikangas $\mathrm{OM}$, Aronen ET, Martin RP, Huttunen MO. Effects of infant temperament and early intervention on the psychiatric symptoms of adolescents. J Am Acad Child Adolesc Psychiatry. 1998;37(10):1070-6.

7. Karalunas SL, Fair D, Musser ED, Aykes K, lyer SP, Nigg JT. Subtyping attentiondeficit/hyperactivity disorder using temperamentdimensions: toward biologically based nosologic criteria. JAMA Psychiatry. 2014;71(9):1015-24.

8. Anzman-Frasca S, Stifter CA, Birch LL. Temperament and childhood obesity risk: a review of the literature. J Dev Behav Pediatr. 2012;33(9):732-45.

9. Hardee JE, Benson BE, Bar-Haim Y, Mogg K, Bradley BP, Chen G, et al. Patterns of neural connectivity during an attention bias task moderate associations between early childhood temperament and internalizing symptoms in young adulthood. Biol Psychiatry. 2013;74(4):273-9.

10. Hartman C, Hopfer C, Corley R, Hewitt J, Stallings M. Using Cloninger's temperament scales to predict substance-related behaviors in adolescents: a prospective longitudinal study. Am J Addict. 2013;22(3):246-51.

11. Lahat A, Perez-Edgar K, Degnan KA, Guyer AE, Lejuez CW, Ernst M, et al. Early childhood temperament predicts substance use in young adults. Transl Psychiatry. 2012;2:e157.

12. Slutske WS, Moffitt TE, Poulton R, Caspi A. Undercontrolled temperament at age 3 predicts disordered gambling at age 32: a longitudinal study of a complete birth cohort. Psychol Sci. 2012;23(5):510-6.

13. Smith AK, Rhee SH, Corley RP, Friedman NP, Hewitt JK, Robinson JL. The magnitude of genetic and environmental influences on parental and observational measures of behavioral inhibition and shyness in toddlerhood. Behav Genet. 2012;42(5):764-77.

14. Spungen $L B$, Farran $A C$. Effect of intensive care unit exposure on temperament in low birth weight preterm infants. J Dev Behav Pediatr. 1986;7(5):288-92.

15. Riese ML. Genetic influences on neonatal temperament. Acta Genet Med Gemellol (Roma). 1990;39(2):207-13.

16. Zhu P, Sun MS, Hao JH, Chen YJ, Jiang XM, Tao RX, et al. Does prenatal maternal stress impair cognitive development and alter temperament characteristics in toddlers with healthy birth outcomes? Dev Med Child Neurol. 2014;56(3):283-9.

17. Bellinger D, Leviton A, Allred E, Rabinowitz M. Pre- and postnatal lead exposure and behavior problems in school-aged children. Environ Res. 1994;66(1):12-30.

18. Boucher O, Jacobson SW, Plusquellec P, Dewailly E, Ayotte P, Forget-Dubois N, et al. Prenatal methylmercury, postnatal lead exposure, and evidence of attention deficit/hyperactivity disorder among Inuit children in Arctic Quebec. Environ Health Perspect. 2012;120(10):1456-61.

19. Hu H, Tellez-Rojo MM, Bellinger D, Smith D, Ettinger AS, Lamadrid-Figueroa $H_{\text {, }}$ et al. Fetal lead exposure at each stage of pregnancy as a predictor of infant mental development. Environ Health Perspect. 2006;114(11):1730-5.

20. Lam HS, Kwok KM, Chan PH, So HK, Li AM, Ng PC, et al. Long term neurocognitive impact of low dose prenatal methylmercury exposure in Hong Kong. Environ Int. 2013;54:59-64.

21. Ronchetti $R$, van den Hazel P, Schoeters G, Hanke W, Rennezova Z, Barreto M, et al. Lead neurotoxicity in children: is prenatal exposure more important than postnatal exposure? Acta Paediatr Suppl. 2006:95(453):45-9.

22. Sagiv SK, Thurston SW, Bellinger DC, Amarasiriwardena C, Korrick SA. Prenatal exposure to mercury and fish consumption during pregnancy and attention-deficit/hyperactivity disorder-related behavior in children. Arch Pediatr Adolesc Med. 2012;166(12):1123-31.

23. Schnaas L, Rothenberg SJ, Flores MF, Martinez S, Hernandez C, Osorio E, et al. Reduced intellectual development in children with prenatal lead exposure. Environ Health Perspect. 2006;114(5):791-7.

24. Cowell WJ, Bellinger DC, Coull BA, Gennings C, Wright RO, Wright RJ. Associations between Prenatal Exposure to Black Carbon and Memory Domains in Urban Children: Modification by Sex and Prenatal Stress. PLoS One. 2015;10(11):e0142492.

25. Barker ED, Kirkham N, Ng J, Jensen SK. Prenatal maternal depression symptoms and nutrition, and child cognitive function. Br J Psychiatry. 2013;203(6):417-21.

26. Dulawa SC. Epigenetic programing of depression during gestation. Bioessays. 2014;36(4):353-8 
27. Musaelyan K, Egeland M, Fernandes C, Pariante CM, Zunszain PA, Thuret S. Modulation of adult hippocampal neurogenesis by early-life environmental challenges triggering immune activation. Neural Plast. 2014;2014:194396.

28. Wright RJ. Moving towards making social toxins mainstream in children's environmental health. Curr Opin Pediatr. 2009;21(2):222-9.

29. Wright RJ. Psychological stress: a social pollutant that may enhance environmental risk. Am J Respir Crit Care Med. 2011;184(7):752-4.

30. Wright RJ, Fisher K, Chiu YH, Wright RO, Fein R, Cohen S, et al. Disrupted prenatal maternal cortisol, maternal obesity, and childhood wheeze. Insights into prenatal programming. Am J Respir Crit Care Med. 2013;187(11):1186-93

31. Deave T, Heron J, Evans J, Emond A. The impact of maternal depression in pregnancy on early child development. BJOG. 2008;115(8):1043-51.

32. Field T. Prenatal depression effects on early development: a review. Infant Behav Dev. 2011;34(1):1-14.

33. Clougherty JE, Kubzansky LD. A framework for examining social stress and susceptibility to air pollution in respiratory health. Cien Saude Colet. 2010;15(4):2059-74.

34. Clougherty JE, Levy Jl, Kubzansky LD, Ryan PB, Suglia SF, Canner MJ, et al. Synergistic effects of traffic-related air pollution and exposure to violence on urban asthma etiology. Environ Health Perspect. 2007;115(8):1140-6.

35. Farley KJ, Meyer JS. Metal mixture modeling evaluation project: 3. Lessons learned and steps forward. Environ Toxicol Chem. 2015;34(4):821-32.

36. Farley KJ, Meyer JS, Balistrieri LS, De Schamphelaere KA, Iwasaki Y, Janssen $\mathrm{CR}$, et al. Metal Mixture Modeling Evaluation project: 2. Comparison of four modeling approaches. Environ Toxicol Chem. 2015;34(4):741-53.

37. Gallagher SS, Rice GE, Scarano LJ, Teuschler LK, Bollweg G, Martin L. Cumulative risk assessment lessons learned: A review of case studies and issue papers. Chemosphere. 2015;120C:697-705.

38. Hicken MT, Adar SD, Diez Roux AV, O'Neill MS, Magzamen S, Auchincloss AH, et al. Do psychosocial stress and social disadvantage modify the association between air pollution and blood pressure?: the multi-ethnic study of atherosclerosis. Am J Epidemiol. 2013;178(10):1550-62.

39. Meyer JS, Farley KJ, Garman ER. Metal mixtures modeling evaluation project: 1. Background. Environ Toxicol Chem. 2015;34(4):726-40.

40. Peters JL, Kubzansky L, McNeely E, Schwartz J, Spiro 3rd A, Sparrow D, et al. Stress as a potential modifier of the impact of lead levels on blood pressure: the normative aging study. Environ Health Perspect. 2007;115(8):1154-9.

41. Shmool JL, Kubzansky LD, Newman OD, Spengler J, Shepard P, Clougherty JE. Social stressors and air pollution across New York City communities: a spatial approach for assessing correlations among multiple exposures. Environ Health. 2014;13:91.

42. Zota AR, Shenassa ED, Morello-Frosch R. Allostatic load amplifies the effect of blood lead levels on elevated blood pressure among middle-aged U.S. adults: a cross-sectional study. Environ Health. 2013;12(1):64.

43. Burris HH, Braun JM, Byun HM, Tarantini L, Mercado A, Wright RJ, et al. Association between birth weight and DNA methylation of IGF2, glucocorticoid receptor and repetitive elements LINE-1 and Alu. Epigenomics. 2013;5(3):271-81.

44. Carrasco AV. The AMAl system of classifying households by socio-economic level: ESOMAR; 2002. (www.esomar.org)

45. Chuang HY, Schwartz J, Gonzales-Cossio T, Lugo MC, Palazuelos E, Aro A, et al. Interrelations of lead levels in bone, venous blood, and umbilical cord blood with exogenous lead exposure through maternal plasma lead in peripartum women. Environ Health Perspect. 2001;109(5):527-32.

46. Hu H, Rabinowitz M, Smith D. Bone lead as a biological marker in epidemiologic studies of chronic toxicity: conceptual paradigms. Environ Health Perspect. 1998;106(1):1-8

47. Hernandez-Avila M, Peterson KE, Gonzalez-Cossio T, Sanin LH, Aro A Schnaas $L$, et al. Effect of maternal bone lead on length and head circumference of newborns and 1-month-old infants. Arch Environ Health. 2002;57(5):482-8

48. $\mathrm{Hu} \mathrm{H}$. Bone lead as a new biologic marker of lead dose: recent findings and implications for public health. Environ Health Perspect. 1998;106 Suppl 4:961-7.

49. Tellez-Rojo MM, Hernandez-Avila M, Lamadrid-Figueroa H, Smith D, Hernandez-Cadena L, Mercado A, et al. Impact of bone lead and bone resorption on plasma and whole blood lead levels during pregnancy. Am J Epidemiol. 2004;160(7):668-78.

50. Mordukhovich I, Wright RO, Hu H, Amarasiriwardena C, Baccarelli A, Litonjua A et al. Associations of toenail arsenic, cadmium, mercury, manganese, and lead with blood pressure in the normative aging study. Environ Health Perspect. 2012;120(1):98-104
51. Bayley N. Bayley Scales of Infant and Toddler Development. San Antonio: The Psychological Corporation; 2006.

52. Chess S, Thomas A, Rutter M, Birch HG. Interaction of temperament and environment in the production of behavioral disturbances in children. Am J Psychiatry. 1963;120:142-8.

53. Carey WB, McDevitt SC. Revision of the Infant Temperament Questionnaire. Pediatrics. 1978;61(5):735-9.

54. Carey WB. A simplified method for measuring infant temperament. J Pediatr. 1970;77(2):188-94

55. Cox JL, Holden JM, Sagovsky R. Detection of postnatal depression. Development of the 10-item Edinburgh Postnatal Depression Scale. Br J Psychiatry. 1987;150:782-6.

56. Cox JL, Chapman G, Murray D, Jones P. Validation of the Edinburgh Postnatal Depression Scale (EPDS) in non-postnatal women. J Affect Disord. 1996;39(3):185-9.

57. Murray D, Cox JL. Screening for depression during pregnancy with the Edinburgh Postnatal Depression Scale (EPDS). J Reprod Infant Psychol. 1990;8:99-106.

58. Murray L, Carothers AD. The validation of the Edinburgh Post-natal Depression Scale on a community sample. Br J Psychiatry. 1990;157:288-90.

59. Boyce P, Stubbs J, Todd A. The Edinburgh Postnatal Depression Scale: validation for an Australian sample. Aust N Z J Psychiatry. 1993;27(3):472-6.

60. Hanington L, Ramchandani P, Stein A. Parental depression and child temperament: assessing child to parent effects in a longitudinal population study. Infant Behav Dev. 2010;33(1):88-95.

61. Kerstis B, Engstrom G, Edlund B, Aarts C. Association between mothers' and fathers' depressive symptoms, sense of coherence and perception of their child's temperament in early parenthood in Sweden. Scand J Public Health. 2013;41(3):233-9.

62. Di Florio A, Forty L, Gordon-Smith K, Heron J, Jones L, Craddock N, et al. Perinatal episodes across the mood disorder spectrum. JAMA Psychiatry. 2013;70(2):168-75

63. Serati M, Redaelli M, Buoli M, Altamura AC. Perinatal Major Depression Biomarkers: A systematic review. J Affect Disord. 2016;193:391-404.

64. Fitzmaurice GM, Laird LM, Ware JH. Applied Longitudinal Analysis. 2nd ed New York: Wiley; 2011

65. Vermunt J, Magidson J. Latent class cluster analysis. In: Hagenaars J, McCutcheon A, editors. Applied Latent Class ANalysis. Cambridge: Cambridge University Press; 2002. p. 89-106.

66. D'Unger A, Land K, McCall P, Nagin D. How mandy latent classes of delinquent/criminal careers? Results from mixed Poisson regression analyses of the London, Philadelphia, and Racine Cohort Studies. Am J Sociol. 1998;103(6):1593-630.

67. Wien) IfSaMoWW. Normal Mixture Modeling fitted via EM algorithm for Model-Based Clustering, Classification, and Density Estimation, including Bayesian regularization. The Comprehensive R Archive Network. http://cran. r-project.org/web/packages/mclust/index.html. Published 2014. Accessed 25 April 2014, 2014

68. Laake LM, Bridgett DJ. Happy babies, chatty toddlers: infant positive affect facilitates early expressive, but not receptive language. Infant Behav Dev. 2014;37(1):29-32.

69. Liu J, Bann C, Lester B, Tronick E, Das A, Lagasse L, et al. Neonatal neurobehavior predicts medical and behavioral outcome. Pediatrics. 2010;125(1):e90-8.

70. Sajaniemi N, Hakamies-blomqvist L, Mäkelä J, Avellan A, Rita H, von Wendt L. Cognitive Development, Temperament and Behavior at 2 Years as Indicative of Language Development at 4 Years in Pre-Term Infants. Child Psychiatry Hum Dev. 2001;31(4):329-46.

71. Team RDC. R: A language and environment for statistical computing. Vienna: R Foundation for Statistical Computing; 2014.

72. Garello V, Viterbori P, Usai MC. Temperamental profiles and language development: a replication and an extension. Infant Behav Dev. 2012;35(1):71-82.

73. Bellinger DC. Future directions for neurobehavioral studies of environmental neurotoxicants. Neurotoxicology. 2001;22(5):645-56.

74. Betts KS, Williams GM, Najman JM, Alati R. Maternal depressive, anxious, and stress symptoms during pregnancy predict internalizing problems in adolescence. Depress Anxiety. 2014;31(1):9-18.

75. Dorrington S, Zammit S, Asher L, Evans J, Heron J, Lewis G. Perinatal maternal life events and psychotic experiences in children at twelve years in a birth cohort study. Schizophr Res. 2014;152(1):158-63.

76. Glasheen C, Richardson GA, Kim KH, Larkby CA, Swartz HA, Day NL. Exposure to maternal pre- and postnatal depression and anxiety symptoms: risk for 
major depression, anxiety disorders, and conduct disorder in adolescent offspring. Dev Psychopathol. 2013;25(4 Pt 1):1045-63.

77. Burns JM, Baghurst PA, Sawyer MG, McMichael AJ, Tong SL. Lifetime low-level exposure to environmental lead and children's emotional and behavioral development at ages 11-13 years. The Port Pirie Cohort Study. Am J Epidemiol. 1999;149(8):740-9.

78. Dietrich KN, Ris MD, Succop PA, Berger OG, Bornschein RL. Early exposure to lead and juvenile delinquency. Neurotoxicol Teratol. 2001;23(6):511-8.

79. Kordas K, Stoltzfus RJ, Lopez P, Rico JA, Rosado JL. Iron and zinc supplementation does not improve parent or teacher ratings of behavior in first grade Mexican children exposed to lead. J Pediatr. 2005;147(5):632-9.

80. Grandjean P, Weihe P, Nielsen F, Heinzow B, Debes F, Budtz-Jorgensen E. Neurobehavioral deficits at age 7 years associated with prenatal exposure to toxicants from maternal seafood diet. Neurotoxicol Teratol. 2012;34(4):466-72.

81. Bohlin G, Hagekull B. Socio-emotional development: from infancy to young adulthood. Scand J Psychol. 2009;50(6):592-601.

82. Nigg JT, Goldsmith HH, Sachek J. Temperament and attention deficit hyperactivity disorder: the development of a multiple pathway model. J Clin Child Adolesc Psychol. 2004;33(1):42-53.

83. Garrido Latorre F, Hernandez-Avila M, Tamayo Orozco J, Albores Medina CA, Aro A, Palazuelos E, et al. Relationship of blood and bone lead to menopause and bone mineral density among middle-age women in Mexico City. Environ Health Perspect. 2003;111(4):631-6.

84. Silbergeld EK. Lead in bone: implications for toxicology during pregnancy and lactation. Environ Health Perspect. 1991;91:63-70.

\section{Submit your next manuscript to BioMed Central and we will help you at every step:}

- We accept pre-submission inquiries

- Our selector tool helps you to find the most relevant journal

- We provide round the clock customer support

- Convenient online submission

- Thorough peer review

- Inclusion in PubMed and all major indexing services

- Maximum visibility for your research

Submit your manuscript at www.biomedcentral.com/submit

) Biomed Central 